\title{
Self-reported diabetes is associated with self-management behaviour: a cohort study
}

\author{
Baiju R Shah*1,2,3 and Douglas G Manuel1,4
}

Address: ${ }^{1}$ Institute for Clinical Evaluative Sciences, Toronto, Canada, ${ }^{2}$ Departments of Medicine and Health Policy, Management and Evaluation, University of Toronto, Toronto, Canada, ${ }^{3}$ Department of Medicine, Sunnybrook Health Sciences Centre, Toronto, Canada and ${ }^{4}$ Department of Public Health Sciences, University of Toronto, Toronto, Canada

Email: Baiju R Shah* - baiju.shah@ices.on.ca; Douglas G Manuel - doug.manuel@ices.on.ca

* Corresponding author

Published: 7 July 2008

BMC Health Services Research 2008, 8:142 doi:10.1 I86/1472-6963-8-142
Received: 16 November 2007

Accepted: 7 July 2008

This article is available from: http://www.biomedcentral.com/I472-6963/8//42

(c) 2008 Shah and Manuel; licensee BioMed Central Ltd.

This is an Open Access article distributed under the terms of the Creative Commons Attribution License (http://creativecommons.org/licenses/by/2.0), which permits unrestricted use, distribution, and reproduction in any medium, provided the original work is properly cited.

\begin{abstract}
Background: The purposes of this cohort study were to establish how frequently people with physician-diagnosed diabetes self-reported the disease, to determine factors associated with selfreporting of diabetes, and to evaluate subsequent differences in self-management behaviour, health care utilisation and clinical outcomes between people who do and do not report their disease.

Methods: We used a registry of physician-diagnosed diabetes as a reference standard. We studied respondents to a 2000/0I population-based health survey who were in the registry $(n=1,8 \mid 2)$, and we determined the proportion who reported having diabetes during the survey. Baseline factors associated with self-report and subsequent behavioural, utilisation and clinical differences between those who did and did not self-report were defined from the survey responses and from linkage with administrative data sources.

Results: Only $75 \%$ of people with physician-diagnosed diabetes reported having the disease. People who did self-report were more likely to be male, to live in rural areas, to have longer disease duration and to have received specialist physician care. People who did not report having diabetes in the survey were markedly less likely to perform capillary blood glucose monitoring in the subsequent two years (OR $0.05,95 \% \mathrm{Cl} 0.02$ to 0.08$)$. They were also less likely to receive specialist physician care $(\mathrm{OR} 0.55,95 \% \mathrm{Cl} 0.37$ to 0.86$)$, and were less likely to require hospital care for hypo- or hyperglycaemia (OR $0.09,95 \% \mathrm{Cl} 0.0 \mathrm{I}$ to 0.28 ).

Conclusion: Many people with physician-diagnosed diabetes do not report having the disease, but most demographic and clinical features do not distinguish these individuals. These individuals are much less likely to perform capillary glucose monitoring, suggesting that their diabetes selfmanagement is inadequate. Clinicians may be able to use the absence of glucose monitoring as a screening tool to identify people needing a detailed evaluation of their disease knowledge.
\end{abstract}

\section{Background}

Chronic disease care in the ambulatory setting is placing increasing emphasis on patient self-management. [1,2] Diabetes care is an example of this approach, as people with the disease are involved in many aspects of their care, including diet, exercise and other lifestyle interventions, self-monitoring of blood glucose levels, regular foot care, medication adherence and adjustment of insulin doses. 
Providing knowledge and skills to self-manage diabetes leads to small to moderate short-term improvements in both glycaemic and blood pressure control. [3,4]

To self-report having diabetes, a person must have at least some cognitive knowledge of the disease. They must recognize the term "diabetes" and associate the term with themselves. Most people who self-report having the condition likely associate diabetes as a risk to their health, although they may also associate diabetes with some positive aspects of their health, such as empowerment to modify their health risk, or membership in a group of similar people. However, not all people who are diagnosed with diabetes will self-report that they have the disease. People may not self-report having diabetes for several reasons: they may never have been properly informed about the diagnosis, they may not understand the term, they may disagree with the diagnosis, they may believe the disease is "cured" because they are managing it appropriately, or they may be hiding the diagnosis because of stigma about diabetes. Regardless of the reasons for not self-reporting diabetes, these people may be less likely to participate in disease self-management and hence may not achieve the best possible health outcomes.

Previous studies have reported that between one-quarter and one-half of people with diagnosed diabetes deny having it on health questionnaires. [5-8] Middle-aged adults were less likely to self-report having diabetes than younger adults or the elderly. $[5,9]$ Some studies reported that women were more accurate, $[10]$ while others suggested that men were. [5,9] Higher education levels resulted in greater rates of self-report. $[6,10,11]$ Patients who do not self-report having diabetes have been found to have worse glycaemic control, [12] but otherwise the clinical consequences have not been studied.

We hypothesized that demographic factors (such as age and education) and clinical factors (such as other illnesses and physician utilisation) would be associated with selfreported diabetes in people with physician-diagnosed diabetes. We also hypothesized that people with diabetes who did not report having the disease would subsequently participate less in self-management behaviours, have reduced health care utilisation, and would therefore have worse clinical outcomes than those who did report their disease.

\section{Methods}

The study base was all community-dwelling non-institutionalised residents of Ontario, Canada with physiciandiagnosed diabetes in 2000/01, aged 20 years or older. The study was approved by the institutional review board of Sunnybrook Health Sciences Centre.

\section{Data sources}

The study was conducted using a population-based disease registry, a population health survey, and health administrative data sources. Individuals were linked between all data sources using their encrypted unique health card number.

Physician-diagnosed diabetes was determined from the Ontario Diabetes Database (ODD), a registry of people with diabetes (excluding gestational diabetes) created from administrative data sources. [13] Diabetes is defined based on physician service claims and hospitalisation records bearing a diagnosis code for diabetes, [14] and the date of diagnosis is determined from the earliest such record. When compared against primary care chart review, the ODD was found to have at least $97 \%$ specificity. [13]

Self-reported diabetes was determined from the Canadian Community Health Survey cycle 1.1 (CCHS). The CCHS provided a cross-sectional estimate of health determinants, health status and health care utilisation in the Canadian population, and was conducted between September 2000 and November 2001 by Statistics Canada. The target population of the survey included household residents across Canada, excluding populations living on aboriginal reserves, military bases and certain remote areas. In Ontario, the sample size was 39,278 respondents, which represented a response rate of 82.0 percent. Of them, 32,848 respondents (83.6 percent) consented to and were successfully linked to administrative data using their encrypted health card number.

Other linked data sources used in this study included: 1) the discharge abstracts database, which provides detailed information on all hospitalisations; 2 ) the physician service claims database, which includes billing claims for consultation, visits and assessments by physicians; and 3) the drug prescription database, which lists prescriptions provided under the provincial formulary for all residents aged $\geq 65$ years. Because of the government-funded universal health care system in Ontario, these data are comprehensive (covering all Ontario residents) and complete (covering virtually all delivered care across settings and across time).

\section{Patient selection}

Adults surveyed in the CCHS who were also recorded in the ODD as having been diagnosed with diabetes by a physician at least six months before their CCHS interview date were selected. The lag allowed time for individuals to receive and understand the diagnosis of diabetes from their physicians. Self-reported diabetes was defined based on the answer to the CCHS question "Do you have diabetes?" 


\section{Variable definitions}

Several factors which could be associated with selfreported diabetes were defined from the CCHS, ODD and other administrative data. These baseline factors were determined as of the date of the CCHS interview. Sociodemographic variables were sex, age, marital status, immigration status, race, rural residence, education level and neighbourhood income level. Health status variables were duration of diabetes, number of other chronic medical conditions, microvascular disease (history of retinal photocoagulation) and macrovascular disease (history of hospitalisation for coronary disease, stroke, non-traumatic lower extremity amputation). Health care utilisation variables were ambulatory care visits with family physicians and diabetes specialist physicians in the year before the CCHS interview.

Subsequent self-management behaviour was assessed by examining whether people filled at least one prescription for capillary glucose test strips within two years after their CCHS interview date. Canadian practice guidelines recommend capillary glucose monitoring for virtually all people with diabetes. [15] Because only people aged $\geq 65$ years are eligible for the provincially-funded drug benefits program, these data were not available for younger people, so they were excluded from this analysis. The measures of subsequent health care utilisation (also measured within two years after the person's CCHS interview date) were: at least one visit for ophthalmological screening with an eye care professional, and at least one ambulatory visit for diabetes specialist care. The time from the CCHS interview to the first occurrence of several clinical outcomes (hospitalisation or emergency department visit for hypo- or hyperglycaemia, hospitalisation for soft-tissue infections or gangrene, hospitalisation for myocardial infarction, and death) were also determined.

\section{Statistical analysis}

To evaluate the factors associated with self-reported diabetes, logistic regression was used with self-reported diabetes as the dependent variable and the baseline factors as independent variables. Both bivariate and multivariate models were built using all factors.

To determine whether subsequent self-management behaviour and health care utilisation were different between people who did and did not self-report having diabetes, we used logistic regression adjusting for all baseline factors. The impact on subsequent clinical outcomes was assessed using Cox proportional hazards regression, adjusting for all baseline factors plus two additional variables from the CCHS: self-perceived health and smoking status. Censoring was at death or the end of follow-up (March 31, 2005). In all models, individuals were weighted based on their sampling weight in the CCHS, and bootstrapping methods were used to determine 95\% confidence intervals around all estimates.

\section{Results}

There were 1,812 people with physician-diagnosed diabetes (according to the reference standard definition of diabetes) who completed the CCHS. Of them, 1,356 (75\%) self-reported having diabetes, while 456 (25\%) did not.

Bivariate and multivariate associations between baseline factors and self-reported diabetes, including odds ratios with 95\% confidence intervals, are presented in Table 1. People who were male, lived in rural areas, with longer diabetes duration and who saw diabetes specialists were more likely to report that they had the disease. Other factors were not statistically significantly associated with selfreported diabetes.

The subsequent differences between those who did and did not report having diabetes are presented in Table 2. People who did not report having diabetes were markedly less likely to perform capillary blood glucose monitoring than those who did. They were also less likely to have specialist physician care, but ophthalmologic screening did not differ. Many of the clinical events were uncommon. Nonetheless, only four of the people who had a hospitalisation or emergency department visit for hypo- or hyperglycaemia had not reported having diabetes in the CCHS; hence, the adjusted hazard ratio for these events was highly statistically significant. Other clinical outcomes did not differ between groups.

\section{Discussion}

More than one in four people with physician-diagnosed diabetes did not self-report having the disease. This frequency is similar to that reported in previous studies. [58] Our findings also showed that people who did not selfreport having diabetes were markedly less likely to perform capillary blood glucose monitoring, an example of the many self-management behaviours expected of people with diabetes. Since self-care is the cornerstone of diabetes management, a substantial portion of the diabetic population may be inadequately managed. The lack of self-identification as being diagnosed with diabetes may occur for many reasons, because of a lack of awareness, belief in or acceptance of the diagnosis. It might also occur because physicians simply did not inform their patients of the diagnosis, or used euphemisms rather than the word "diabetes". Individuals who do not self-identify as having diabetes may not be aware of the attendant risks to their health. They may also be less likely to respond to public education messages about diabetes, and if they do not report having the disease to their physicians and other health care providers, diabetes may not be taken into 
Table I: Bivariate and multivariate associations of baseline factors with self-reported diabetes.

\begin{tabular}{|c|c|c|c|c|}
\hline \multicolumn{2}{|c|}{ Predictor } & \multirow{2}{*}{$\begin{array}{c}\begin{array}{c}\text { Frequency of self- } \\
\text { reported diabetes (\%) }\end{array} \\
681 / 886(77)\end{array}$} & \multirow{2}{*}{$\begin{array}{c}\begin{array}{c}\text { Weighted bivariate OR } \\
(95 \% \mathrm{CI})\end{array} \\
1.00 \mathrm{ref}\end{array}$} & \multirow{2}{*}{$\begin{array}{c}\text { Weighted multivariate } \\
\text { OR }(95 \% \mathrm{Cl}) \\
1.00 \mathrm{ref}\end{array}$} \\
\hline Sex & Male & & & \\
\hline & Female & $675 / 926(73)$ & $0.72(0.52-0.98)$ & $0.63(0.44-0.87)$ \\
\hline \multirow[t]{3}{*}{ Age } & $18-44$ & $150 / 2 \mid 2(7 \mid)$ & $0.70(0.44-1.12)$ & $0.93(0.54-1.73)$ \\
\hline & $45-64$ & $490 / 64 I(76)$ & $1.00(0.69-1.44)$ & $1.22(0.8 \mathrm{I}-1.86)$ \\
\hline & $65+$ & $716 / 959(75)$ & $1.00 \mathrm{ref}$ & 1.00 ref \\
\hline \multirow[t]{3}{*}{ Marital status } & Married & $750 / 1012(74)$ & 1.00 ref & $1.00 \mathrm{ref}$ \\
\hline & Widowed/Divorced & $478 / 631(76)$ & $1.26(0.90-1.84)$ & $1.31(0.89-2.00)$ \\
\hline & Single & $128 / 169(76)$ & $1.17(0.70-2.10)$ & $1.24(0.68-2.32)$ \\
\hline \multirow[t]{2}{*}{ Immigrant } & No & $1056 / 1393(76)$ & $1.00 \mathrm{ref}$ & $1.00 \mathrm{ref}$ \\
\hline & Yes & $300 / 419(72)$ & $0.76(0.53-1.08)$ & $0.80(0.52-1.20)$ \\
\hline \multirow[t]{2}{*}{ Race } & White & $|239 /| 64 \mid(76)$ & 1.00 ref & 1.00 ref \\
\hline & Non-White & $117 / 17 \mid(68)$ & $0.82(0.5 \mathrm{I}-\mathrm{I} .28)$ & $1.03(0.60-1.72)$ \\
\hline \multirow[t]{2}{*}{ Rural residence } & No & $1072 / 1442(74)$ & 1.00 ref & 1.00 ref \\
\hline & Yes & $284 / 370(77)$ & $1.52(1.10-2.22)$ & $1.59(I .06-2.4 I)$ \\
\hline \multirow[t]{4}{*}{ Education level } & Less than high school & $603 / 790(76)$ & 1.00 ref & 1.00 ref \\
\hline & Graduated high school & $232 / 310(75)$ & $0.94(0.58-1.52)$ & $1.04(0.64-1.72)$ \\
\hline & Some post-secondary & $85 / 111$ (77) & $1.02(0.57-1.99)$ & $0.91(0.46-1.81)$ \\
\hline & Graduated post-secondary & $436 / 601(73)$ & $0.93(0.64-1.33)$ & $0.97(0.63-1.49)$ \\
\hline \multirow[t]{5}{*}{ Income quintile } & Lowest & $337 / 434(78)$ & $1.00 \mathrm{ref}$ & $1.00 \mathrm{ref}$ \\
\hline & 2 & $305 / 421$ (72) & $0.65(0.40-1.09)$ & $0.63(0.36-1.08)$ \\
\hline & 3 & $272 / 364(75)$ & $0.74(0.44-1.20)$ & $0.78(0.45-1.30)$ \\
\hline & 4 & $235 / 319(74)$ & $0.75(0.44-1.27)$ & $0.78(0.45-1.35)$ \\
\hline & Highest & $207 / 274(76)$ & $0.79(0.46-1.29)$ & $0.8 I(0.45-1.4 I)$ \\
\hline \multirow[t]{3}{*}{ Diabetes duration } & 6 months to 2 years & $164 / 269(61)$ & 1.00 ref & 1.00 ref \\
\hline & 2 to 5 years & $335 / 479(70)$ & $1.56(0.96-2.49)$ & $1.78(1.07-2.89)$ \\
\hline & $5+$ years & $857 / 1064(81)$ & $2.69(1.62-4.13)$ & $2.82(1.66-4.43)$ \\
\hline \multirow[t]{3}{*}{ Other chronic conditions } & 0 & $756 / 1031$ (73) & $1.00 \mathrm{ref}$ & 1.00 ref \\
\hline & 1 & $405 / 529$ (77) & $1.40(0.98-2.05)$ & $1.19(0.80-1.85)$ \\
\hline & 2 or more & $195 / 252$ (77) & $1.19(0.70-2.16)$ & $1.01(0.60-1.91)$ \\
\hline \multirow[t]{2}{*}{ Microvascular disease } & No & $1316 / 1769(74)$ & 1.00 ref & $1.00 \mathrm{ref}$ \\
\hline & Yes & $40 / 43(93)$ & $1.85(0.54-8)$ & $1.83(0.77-8)$ \\
\hline \multirow[t]{2}{*}{ Macrovascular disease } & No & $1240 / 1674(74)$ & 1.00 ref & 1.00 ref \\
\hline & Yes & $116 / 138(84)$ & $1.22(0.69-2.57)$ & $0.8 \mathrm{I}(0.4 \mathrm{I}-\mathrm{I} .84)$ \\
\hline \multirow[t]{3}{*}{ Family physician visits } & 0 to 6 & $585 / 812(72)$ & 1.00 ref & $1.00 \mathrm{ref}$ \\
\hline & 7 to 12 & $328 / 422(78)$ & $1.25(0.86-1.87)$ & $1.31(0.87-2.09)$ \\
\hline & 13 or more & $443 / 578$ (77) & $1.24(0.85-1.91)$ & $1.18(0.76-2.01)$ \\
\hline \multirow[t]{2}{*}{ Specialist visits } & No & $917 / 1271$ (72) & 1.00 ref & 1.00 ref \\
\hline & Yes & $439 / 54 I(8 I)$ & $1.90(1.34-2.79)$ & $1.95(1.34-2.96)$ \\
\hline
\end{tabular}

account in treatment plans for their other health conditions.

To overcome this barrier to care and to encourage patient self-management, clinicians may want to identify people who do not self-report having diabetes. The baseline factors most strongly associated with self-reported diabetes were longer duration of diabetes and specialist care for the disease. These are perhaps not surprising, as those who have had diabetes for more time and who are attending a specialist clinic to treat it should be more likely to disclose having the disease. However, the other factors that might have been expected to be associated with self-report (such as education, income, ethnicity or the presence of other chronic diseases) in fact were not, so clinicians cannot rely on these factors to identify individuals who do not report having the disease. In fact, capillary glucose monitoring may be a marker to identify such people. Monitoring may reflect individuals' knowledge and understanding of diabetes and their engagement in its treatment, so clinicians may be able to use the absence of this self-management behaviour as a screening tool to identify individuals needing a more detailed assessment of their comprehension of diabetes and its management.

Unlike previous studies examining self-reported diabetes, this study included a large number of people and was population-based, and hence had greater power to detect factors associated with self-report and differences in care between those who did and did not report having diabetes. An important limitation, however, is the absence of important clinical and behavioural measures that could 
Table 2: Subsequent differences between subjects who did and did not report having diabetes.

\begin{tabular}{lcc}
\hline Measure & & \\
\hline Self-management behavior & Overall frequency & Weighted adjusted OR (95\% CI)* \\
\hline Capillary blood glucose monitoring ${ }^{\dagger}$ & $63.1 \%$ & $0.05(0.02-0.08)$ \\
\hline Health care utilization & Overall frequency & Weighted adjusted OR (95\% CI) \\
\hline Ophthalmologic exam & $74.3 \%$ & $0.82(0.56-1.22)$ \\
Specialist visit & $41.9 \%$ & $0.55(0.37-0.86)$ \\
\hline Clinical outcomes & Overall event occurrence & Weighted adjusted HR (95\% Cl) * \\
\hline Hypo- or hyperglycemia & $4.8 \%$ & $0.09(0.01-0.28)$ \\
Soft tissue infection or gangrene & $3.1 \%$ & $0.47(0.11-1.28)$ \\
Myocardial infarction & $5.5 \%$ & $0.92(0.32-1.50)$ \\
Death & $13.9 \%$ & $1.02(0.67-1.59)$ \\
\hline
\end{tabular}

* Subjects who self-reported having diabetes are the reference group.

t This measure was determined only in subjects $\geq 65$ years $(n=959)$.

be more influenced by the failure to self-report diabetes than the health service utilisation and outcomes measures used. In addition, a more detailed survey would be needed to discern the potential psychological and behavioural reasons why some people may fail to self-report diabetes. The reference standard definition of diabetes we used for physician-diagnosed diabetes was an administrative-data derived disease registry. While a validation study suggested excellent specificity ( $\geq 97 \%$ ), false positives will occur. [13] Such people would be categorized as failing to self-report diabetes, even though they genuinely do not have the disease. Although the registry excludes gestational diabetes, some such patients may have been inadvertently captured, which might explain the apparently lower frequency of self-report among women.

Differences in health service utilisation between those who do and do not self-report having diabetes have not been evaluated previously. The study found that ophthalmologic screening examinations occurred whether or not people reported having diabetes, but people who did not report diabetes were less likely to receive specialist physician care for diabetes in the following two years, even after adjusting for baseline specialist utilisation and diabetes severity. This finding suggests that patients may need to advocate on their own behalf for referral to diabetes specialists, which those not reporting diabetes may be less likely to do. It also suggests that primary care physicians are far more likely than specialists to have to identify people who do not report having diabetes and to overcome this potential barrier to care.

The failure to self-identify disease has been studied in other diseases, where important consequences have been noted. People who did not report having hypercholesterolemia made fewer dietary changes than those who did, [16] corroborating the effect of self-report on self-management behaviour. Denial of illness predicted worse survival in colon cancer. [17] Following acute myocardial infarction or coronary artery by-pass surgery, patients who did not acknowledge the seriousness of their illness were more noncompliant with treatment and spent more days readmitted to hospital during the following year. [18] In contrast, several studies have documented that women with breast cancer who did not report having the disease had better long-term survival than those who acknowledged the disease, even when controlling for tumour staging, treatments performed and other prognostic factors. [19-21]

\section{Conclusion}

A large proportion of people with physician-diagnosed diabetes do not self-report that they have the disease, which may in part reflect physicians' failure to appropriately convey the diagnosis. These individuals are less likely to perform capillary blood glucose monitoring, a marker of self-management behaviour. Since self-care is a foundation of the treatment for chronic diseases, these individuals' diabetes may not be ideally managed. Sociodemographic factors do not help clinicians identify people do not report their disease. Clinicians, particularly primary care practitioners, must identify such individuals to ensure that they are aware of and acknowledge their diagnosis, and are adequately educated about its optimal management. 


\section{Abbreviations \\ CCHS: Canadian Community Health Survey; ODD: Ontario Diabetes Database.}

\section{Competing interests}

The authors declare that they have no competing interests.

\section{Authors' contributions}

BRS conceived of the study, participated in the design of the study and wrote the manuscript. DGM participated in the design of the study. Both authors read and approved the final manuscript.

\section{Acknowledgements}

We would like to acknowledge the assistance of Mr. Laurence Chong for the analysis of the data. The study was funded by the Canadian Diabetes

Association. Dr. Shah is supported as a Clinician-Scientist by the Canadian Institutes of Health Research and the Canadian Diabetes Association.

\section{References}

I. Holman H, Lorig K: Patient self-management: a key to effectiveness and efficiency in care of chronic disease. Public Health Rep 2004, I I 9:239-243.

2. Newman S, Steed L, Mulligan K: Self-management interventions for chronic illness. Lancet 2004, 364: I523-I537.

3. Norris SL, Engelgau MM, Narayan KMV: Effectiveness of self-management training in type 2 diabetes: A systematic review of randomized controlled trials. Diabetes Care 200I, 24:56I-587.

4. Warsi A, Wang PS, LaValley MP, Avorn J, Solomon DH: Self-management education programs in chronic disease: a systematic review and methodological critique of the literature. Arch Intern Med 2004, I 64: I64I- I649.

5. Martin LM, Leff M, Calonge N, Garrett C, Nelson DE: Validation of self-reported chronic conditions and health services in a managed care population. Am J Prev Med 2000, I 8:2I5-218.

6. Wu SC, $\mathrm{Li} \mathrm{CY,} \mathrm{Ke} \mathrm{DS:} \mathrm{The} \mathrm{agreement} \mathrm{between} \mathrm{self-reporting}$ and clinical diagnosis for selected medical conditions among the elderly in Taiwan. Public Health 2000, I | 4: | 37- I 42.

7. Manuel DG, Schultz SE: Using linked data to calculate summary measures of population health: Health-adjusted life expectancy of people with diabetes mellitus. Popul Health Metr 2004 2:4.

8. Molenaar EA, Ameijden EJC, Grobbee DE, Numans ME: Comparison of routine care self-reported and biometrical data on hypertension and diabetes: results of the Utrecht Health Project. Eur J Public Health 2007, I 7:199-205.

9. Goldman N, Lin IF, Weinstein M, Lin YH: Evaluating the quality of self-reports of hypertension and diabetes. J Clin Epidemiol 2003, 56:148-I54.

10. Kriegsman DMW, Penninx BWJH, van Eijk JTM, Boeke AJP, Deeg $\mathrm{DJH}$ : Self-reports and general practitioner information on the presence of chronic diseases in community dwelling elderly. J Clin Epidemiol 1996, 49:|407-|4I7.

II. Mackenbach JP, Looman CWN, van der Meer JBW: Differences in the misreporting of chronic conditions, by level of education: The effect on inequalities in prevalence rates. Am J Public Health 1996, 86:706-7II.

12. Garay-Sevilla ME, Malacara JM, Gutiérrez-Roa A, González E: Denia of disease in type 2 diabetes mellitus: its influence on metabolic control and associated factors. Diabet Med 1999, 1 6:238-244.

13. Hux JE, Ivis F, Flintoft V, Bica A: Diabetes in Ontario: determination of prevalence and incidence using a validated administrative data algorithm. Diabetes Care 2002, 25:5।2-5।6.

14. Clottey C, Mo F, LeBrun B, Mickelson P, Niles J, Robbins G: The development of the National Diabetes Surveillance System (NDSS) in Canada. Chronic Dis Can 2001, 22:67-69.

15. Canadian Diabetes Association Clinical Practice Guidelines Expert Committee: Canadian Diabetes Association 2003 clinical prac- tice guidelines for the prevention and management of diabetes in Canada. Can J Diabetes 2003, 27:SI-SII5.

16. Irvine MJ, Logan AG: Is knowing your cholesterol number harmful? I Clin Epidemiol 1994, 47: | 3 |- | 45

17. Thomas C, Turner P, Madden F: Coping and the outcome of stoma surgery. J Psychosom Res 1988, 32:457-467.

18. Levine J, Warrenburg S, Kerns R, Schwartz G, Delaney R, Fontana A Gradman A, Smith S, Allen S, Cascione R: The role of denial in recovery from coronary heart disease. Psychosom Med I987, 49:109-117.

19. Greer S, Morris T, Pettingale KW, Haybittle JL: Psychological response to breast cancer and I5-year outcome. Lancet 1990 335:49-50.

20. Greer S, Morris T, Pettingale KW: Psychological response to breast cancer: effect on outcome. Lancet 1979, 3 | 4:785-787.

21. Dean C, Surtees PG: Do psychological factors predict survival in breast cancer? J Psychosom Res 1989, 33:561-569.

\section{Pre-publication history}

The pre-publication history for this paper can be accessed here:

http://www.biomedcentral.com/1472-6963/8/142/pre pub

Publish with BioMed Central and every scientist can read your work free of charge

"BioMed Central will be the most significant development for disseminating the results of biomedical research in our lifetime. "

Sir Paul Nurse, Cancer Research UK

Your research papers will be:

- available free of charge to the entire biomedical community

- peer reviewed and published immediately upon acceptance

- cited in PubMed and archived on PubMed Central

- yours - you keep the copyright 